\title{
Analysis of Recombinant CD24 Glycans by MALDI-TOF-MS Reveals Prevalence of Sialyl-T Antigen
}

\author{
Edwin Motari ${ }^{\mathrm{a}}$, Xincheng Zheng ${ }^{\mathrm{b}}$, Xiaodan Su ${ }^{\mathrm{e}}$, Yang Liu ${ }^{\mathrm{c}, *}$, Mamuka Kvaratskhelia ${ }^{\mathrm{d}, *}$, \\ Michael Freitas $^{\mathrm{e}^{*}}$, Peng George Wang ${ }^{\mathrm{a}, *}$
}

\author{
${ }^{a}$ Departments of Chemistry and Biochemistry, The Ohio State University, Columbus, OH 43210, USA \\ ${ }^{b}$ OncoImmune, Inc. Columbus, OH 43212, USA \\ ${ }^{\mathrm{c}}$ Department of Surgery and Internal Medicine, University of Michigan, Ann Harbor, MI 48109, USA \\ ${ }^{\mathrm{d}}$ Center for Retrovirus Research and Comprehensive Cancer Center, College of Pharmacy, The Ohio State University, \\ Columbus, OH 43210, USA \\ ${ }^{\mathrm{e}}$ Department of Molecular Virology, Immunology \& Medical Genetics, School of Biomedical Science, College of \\ Medicine, The Ohio State University, Columbus, OH 43210, USA \\ *Corresponding author. Fax: 1-614-688-3106 \\ Email address: wang.892@osu.edu; yangl@med.umich.edu; kvaratskhelia.1@osu.edu; freitas.5@osu.edu
}

Received: 8 August 2008; | Revised: 12 October 2008; | Accepted: 18 October 2008

\begin{abstract}
CD24 is a glycosyl-phosphatidyl-inositol linked glycoprotein expressed in a broad range of cell types and is heavily glycosylated. It has been found to be over expressed in cancers and tumors and is also a costimulatory molecule. Therefore, this study was carried out to define the structures of the carbohydrates associated with the CD24 recombinant protein. The CD24 glycoprotein's oligosaccharides were released by chemical and enzymatic means prior to being analyzed by MALDI-TOF-MS. The results obtained showed that CD24 is both $\mathrm{N}$ - and O-glycosylated. The major oligosaccharides were found to be Neu5Ac $\alpha-2,3 / 6 \mathrm{Gal} \beta$ 1,3GalNAc, NeuAc $\mathrm{Cal}_{2} \beta-1,3 \mathrm{GalNAc}_{1}$ (O-glycans), GalNAc $\mathrm{GlcNAc}_{2} \mathrm{Man}_{3} \mathrm{Fuc}_{1}$,

$\mathrm{Gal}_{1} \mathrm{GalNAc}_{2} \mathrm{GlcNAc}_{2} \mathrm{Man}_{3} \mathrm{Fuc}_{1}$, and Gal $\mathrm{GalNAc}_{2} \mathrm{GlNNAc}_{2} \mathrm{Man}_{3} \mathrm{Fuc}_{1}$ (N-glycans). The results showed that Neu5Ac $\alpha-2,3 / 6 \mathrm{Gal} \beta-1,3 \mathrm{GalNAc}$ (sialyl-tumor antigen, sT), a cancer-associated carbohydrate, was the most abundant glycan associated with CD24. This result raised the intriguing possibility that CD24 may be a major carrier of the sialyl-T abundantly found in cancer cells.
\end{abstract}

Keywords: CD24; Glycans; MALDI-TOF-MS; T antigen

\subsection{Introduction}

CD24 is a glycosyl-phosphatidyl-inositol (GPI)-anchored glycoprotein with widespread expression in both hematopoietic and nonhematopoietic cells. The protein is composed of
27-35 amino acids with nearly half of the amino acids being serine and threonine $[1,2]$. Both serine and threonine are potential sites for $\mathrm{O}$ glycosylation and asparagine gives potential for $\mathrm{N}$-glycosylation. The human form of CD24 has an unusual structure with the core having only 31 
amino acids [3]. The CD24 molecule is expressed in developing or regenerating tissue and in pre-Bcells, granulocytes, keratinocytes, and renal tubular epithelial cells $[1,4,5]$. CD24 is overexpressed in both hematological malignancies and a variety of solid tumors such as gastric, renal, nasopharyngeal, hepatocellular, colonic, and small cell lung carcinomas $[6,7]$.

The CD24 gene has been implicated in immunity, cancer and autoimmune diseases. Thus, expressing of CD24 in non-professional antigenpresenting cells, such as activated B cells [8, 9], astrocytes and oligodendritic cells $[10,11]$ conveys a potent costimulatory activity. In $\mathrm{T}$ cells, CD24 promotes homeostatic proliferation [12]. In contrast, CD24 expression in dendritic cells is a negative regulator that modulates the pace of homeostatic proliferation [13], a process that is important for development of autoimmune diseases and cancer immunotherapy [14, 15]. Expression of CD24 in pre-B cells on the other hand, modulates fibronectin/VLA-4:VCAM-1 interactions [16, 17]. Outside the immune system, CD24 expressed in the central nervous system (CNS) has been shown to inhibit neurite growth [18]. In humans, CD24 polymorphism controls risk and progression of autoimmune diseases, such as multiple sclerosis [19]. Concerning cancerous cells, CD24 has been found to be prevalent on many tumors and carcinomas [20-22]. Carbohydrates of CD24 on tumor cells have been shown to play an important role in metastasis by interaction with P-selectin [23-25]. The interaction of P-selectin and sialylLewisX carbohydrates is essential for CD24-mediated rolling of tumor cells. P-selectin is an adhesion receptor on platelets and activated endothelial cells. This process is necessary for the cancer cells to reach outside of the vascular system and facilitate metastasis [5]. CD24 expression is a prognostic marker in breast cancer, ovarian cancer, and prostate cancer $[4,5,26]$.

Based on the variation in molecular weight, it has been suggested that CD24 is differentially glycosylated in different cell types. Indeed, about $50 \%$ of the 27-31 amino acids in mature CD24 protein are potential anchors for either O- or Nlinked oligosaccharides $[2,27]$. The diversity of CD24 glycosylation may be partly responsible for the wide range of functions ascribed to CD24 by genetic and immunological analyses. The Nglycan analysis of CD24 from different cell lines (lymphoblastoma, neuroblastoma and astrocystoma) and brain homogenates from mouse and human have been analyzed by Ohl etal [3]. The study showed the presence of fucosylated and sialylated complex and hybrid N-glycans. However, the O-glycan composition of CD24 has not been characterized. Here we used MALDITOF-MS to analyze both $\mathrm{O}$ - and N-linked oligosaccharides released from the recombinant CD24 protein by chemical and enzymatic methods. Our data demonstrated that the overwhelming majority of the oligosaccharides are Neu5Ac Gal $\beta-1,3$ GalNAc, namely sialyl-T. These data, together with frequent elevation of CD24 protein in cancer tissues, raised the intriguing possibility that $\mathrm{CD} 24$ protein is a major carrier of the sialyl-T on cancer tissues.

\subsection{Methods and Materials}

\subsection{Materials}

The human CD24IgG1 protein, comprising the first 30 amino acid of human CD24 protein (SETTTGTSSNSSQSTSNSGLAPNPTNATTK) and the IgG1 Fc, was produced in Chinese hamster ovary $(\mathrm{CHO})$ cells and purified by ionexchange and protein A-based affinity chromatography to homogeneity. All chemicals and reagents unless otherwise stated were obtained from Sigma-Aldrich (St. Louis, MO, USA). HPLC grade water, acetonitrile, methanol and n-propanol were purchased from Burdick and Johnson (Muskegon, MI, USA). 2, 5 dihydroxybenzoic acid and acetic acid were purchased from Acros Organics (New Jersey, USA).

\subsection{Chemical cleavage by $\beta$-elimination}

Since IgG contains no O-linked oligosaccharides [28], the CD24IgG1 was freeze dried and the O-glycans released by the ammonia based $\beta$-elimination method introduced by Huang et al. [29]. In this study, ice-cold ethanol was added to precipitate the peptides after boric acid removal. Centrifugation was carried out and the supernatant which contained the sugars decanted for further analysis. 
The O-glycans that were analyzed by tandem mass spectrometry were released by the $\beta$ elimination method according to Kotani and coworkers [30].

\subsection{Cleavage of CD24 from CD24IgG1 with papain}

Since the $\operatorname{IgG}$ is known to contain $\mathrm{N}$-glycans, we cleaved the Fc fragment off in order to focus on the N-glycans from the CD24 glycoprotein. A $20 \mathrm{mg} / \mathrm{mL}$ solution of CD24IgG1 in PBS buffer was prepared followed by addition of $0.1 \mathrm{mg} / \mathrm{mL}$ papain in digestion solution [31]. This mixture was incubated for $5 \mathrm{~h}$ in a circulating water bath set at $37{ }^{\circ} \mathrm{C}$. The reaction was quenched by the addition of $400 \mu \mathrm{L} 0.3 \mathrm{M}$ iodoacetamide. This solution $(3 \mathrm{~mL})$ was dialyzed overnight at $4{ }^{\circ} \mathrm{C}$ against a 3500 MWCO dialysis membrane and freeze dried.

\subsection{Separation of the CD24 from the IgG1 components}

The separation of the CD24 from the fragmented CD24IgG1 was carried out by using a Protein A-Sepharose from Staphylococcus aureus affinity column based on the manufacturer's protocol. The column was prepared by mixing 0.5 g of Protein A-Sepharose with $2.5 \mathrm{~mL}$ buffer A (prepared by adjusting $0.02 \mathrm{M} \mathrm{NaH}_{2} \mathrm{PO}_{4}+0.15$ $\mathrm{M} \mathrm{NaCl}$ to $\mathrm{pH} \mathrm{8.0)} \mathrm{and} \mathrm{allowing} \mathrm{to} \mathrm{stand} \mathrm{for} \mathrm{about}$ $45 \mathrm{~min}$ to swell. The swollen resin was mixed with buffer A $(1: 1, \mathrm{v} / \mathrm{v})$ and poured into the column. The solvent was allowed to drain while the resin settled. This was later washed with 20 column volumes (CVs) of buffer A. After introducing the sample into the column, $10 \mathrm{CV}$ s of buffer A was used to elute the CD24 components from the column. The Fc component and the unfragmented CD24IgG1 was eluted with $3 \mathrm{CVs}$ of buffer B (prepared by mixing $25.7 \mathrm{~mL} 0.2 \mathrm{M} \mathrm{Na} \mathrm{Na}_{2} \mathrm{PO}_{4}$, $24.3 \mathrm{~mL} 0.1 \mathrm{M}$ citric acid and $50.0 \mathrm{~mL}$ deionized water). SDS-PAGE was used to test the purity of collected fractions and compared with the unfragmented CD24IgG1 and the fragmented CD24IgG1.

\subsection{CD24 treatment with PNGase F}

CD24 was treated with PNGase F (SigmaAldrich) according to the manufacturer protocol. In the procedure, $1.0 \mathrm{mg}$ of the $\mathrm{CD} 24$ obtained after papain cleavage and purification was dissolved in $900 \mu \mathrm{L}$ of $20 \mathrm{mM}$ ammonium bicarbonate $\mathrm{pH} 8.0$ and to this solution $100 \mu \mathrm{L}$ of denaturalization solution was added $(0.2 \%$ SDS containing $100 \mathrm{mM}$ 2-mercaptoethanol). The solution was placed for 10 minutes in boiling water to denature the glycoprotein. The solution was allowed to cool and $10 \mathrm{U}$ of PNGase F added to this reaction mixture and incubated at $37{ }^{\circ} \mathrm{C}$ for $20 \mathrm{~h}$. Then $10 \mu \mathrm{L}$ was taken after the incubation to monitor the cleavage of the $\mathrm{N}$-glycans with SDSPAGE.

The reaction mixture was first freeze dried and then desalted and deproteinized using a nonporous graphitized carbon carbograph column (Alltech, Deerfield, IL, USA) [32]. The carbograph column was washed with three CVs of $80 \%$ acetonitrile in water (v/v) with $0.1 \%(\mathrm{v} / \mathrm{v})$ trifluoroacetic acid, followed by three CVs of deionized water. The sample was dissolved in a small amount of water and introduced into the column. The salts and buffer were eluted with 2 $\mathrm{mL}$ of ultra-pure water and neutral $\mathrm{N}$-glycans were recovered with $2 \mathrm{~mL}$ of $25 \%(\mathrm{v} / \mathrm{v})$ acetonitrile in ultrapure water. Acidic N-glycans were eluted with $2 \mathrm{~mL}$ of $25 \%(\mathrm{v} / \mathrm{v})$ acetonitrile in water with $0.05 \%(\mathrm{v} / \mathrm{v})$ trifluoroacetic acid. The collected eluates were freeze dried and stored at $20{ }^{\circ} \mathrm{C}$ for mass spectrometry analysis.

\subsection{Permethylation of the glycans from CD24}

The dried sample, typically $50 \mu \mathrm{g}$, was dissolved in $50 \mu \mathrm{L}$ DMSO with a trace of deionized water [33]. To this mixture $22 \mu \mathrm{L}$ methyl iodide was added and the sample immediately placed in a spin column packed with sodium hydroxide that had been cleaned with DMSO. The sample was recovered by centrifuging at $1000 \mathrm{rpm}$ for $1 \mathrm{~min}$, and washed again with $100 \mu \mathrm{L}$ DMSO. The permethylated Nglycans were recovered by extracting with $3 \times 100$ $\mu \mathrm{L}$ chloroform. The chloroform fractions were combined and washed with $6 \times 200 \mu \mathrm{L}$ DI water. The glycans were dried using a CentriVap ${ }^{\circledR}$ and stored at $-20{ }^{\circ} \mathrm{C}$ for analysis.

\subsection{MALDI-TOF-MS}

A Bruker Esquire - LC/MS (Brucker Daltonics, MA, USA) was used for tandem mass spectrometry and MALDI-TOF-MS was acquired 
with a Kratos Axima-CFR instrument (Shimadzu, MA, USA). For ESI, samples were dissolved in $50 \%$ methanol containing $1 \%$ acetic acid and directly infused into the mass spectrometer. The nebulizing gas was set at $10 \mathrm{psi}$; the dry gas at 6 $\mathrm{L} / \mathrm{min}$; and the dry temperature at $250{ }^{\circ} \mathrm{C}$.

MALDI-TOF mass spectrometry was performed by use of a Kratos Axima-CFR instrument in the positive reflectron mode. The instrument was equipped with a pulsed nitrogen laser set at 337 $\mathrm{nm}$. The acceleration voltage was $20 \mathrm{kV}$ в samples were normally dissolved in a $1: 1$ methanol/water solution containing $2 n \mathrm{mM}$ sodium acetate. A $10 \mathrm{mg} / \mathrm{mL}$ matrix was ${ }_{{ }_{r-4}}^{148}$ ared by dissolving 2, 5-dihydroxy benzoic ac ${ }_{98}$ the above solvent without the sodium aceti ${ }_{64}$-33]. The sample and the matrix were mixed 1: I nefore spotting on the plate and air dried.

\subsection{Results and discussion}

\subsection{Cleavage of the CD24 from CD24IgG1 with} papain and its purification

CD24IgG1 consists of the extr ${ }^{11}$ ular domain of the CD24 protein and the Fc trazınent of IgG1. As shown in Figure 1a, the purified CD24 protein is a covalent dimer. Isoelectrofocusing revealed a complex pattern of the fusion protein, which is consistent with the extensive and diverse glycosylation of the fusion protein. In order to focus on CD24 portion, the CD24IgG1 was cleaved with crystalline papain at the hinge region and its fragmentation monitored with SDS-PAGE. Since no reducing reagent is present in the digestion reaction, papain yield $\mathrm{Fc}$ monomer and CD24 dimer [34]. The fragment components were purified with a protein A Sepharose column in which the Fc region of IgG1 and the unfragmented CD24IgG1 are bound while the CD24 fragment is not. The purification was also monitored with SDS-PAGE and the gel is shown in Figure 1b. The band for the CD24 glycoprotein was relatively pure at an approximate MW of $45 \mathrm{kDa}$ on the non reducing SDS-PAGE gel. This CD24 dimer was used for analysis of Nglycans.
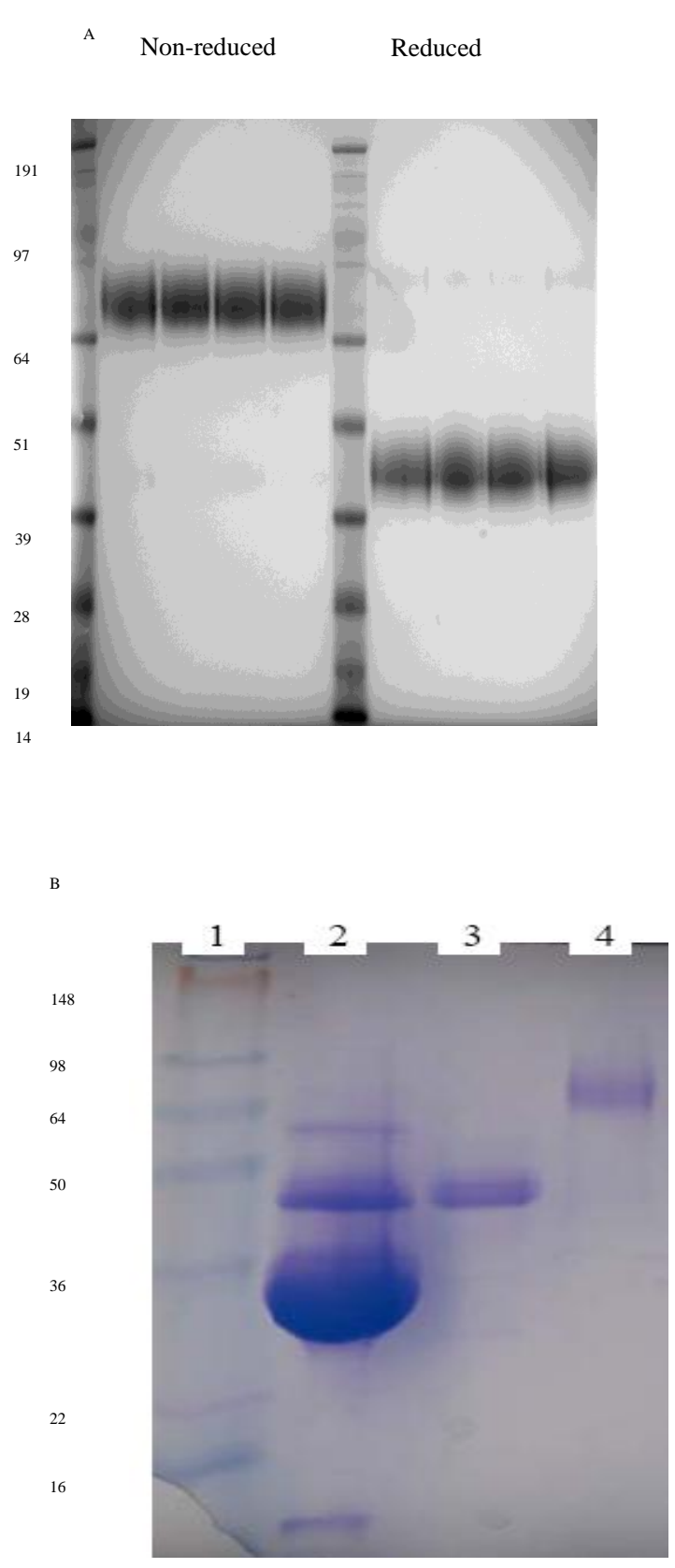

Fig. 1(a) Polyacrylamide gel electrophoresis (PAGE) of the purified fused CD24 protein carried out under either non-reducing or reducing conditions. In each analysis $\sim 2$ and $5 \mathrm{ug}$ was loaded per well in quadruplicate and the gels were stained using Colloidal Blue stain.

(b) non-reducing SDS-PAGE after fragmentation with papain and purification with affinity column: line1 MW marker, line 2: the bound portion containing the Fc part of $\mathrm{IgG}$ in $\mathrm{CD} 24 \mathrm{IgG} 1$, line 3: the CD24, line 4 CD24IgG1. 


\subsection{MALDI-TOF-MS of the released O-glycans}

The released O-glycans from CD24IgG were analyzed with MALDI-TOF-MS and the scan performed in the positive mode. Figure 2 shows the mass spectra of $\mathrm{O}$ - and $\mathrm{N}$-glycans released from the CD24 glycoprotein. This means that the ammonia-based $\beta$-elimination method not only releases the O-glycans, but also N-glycans [29].

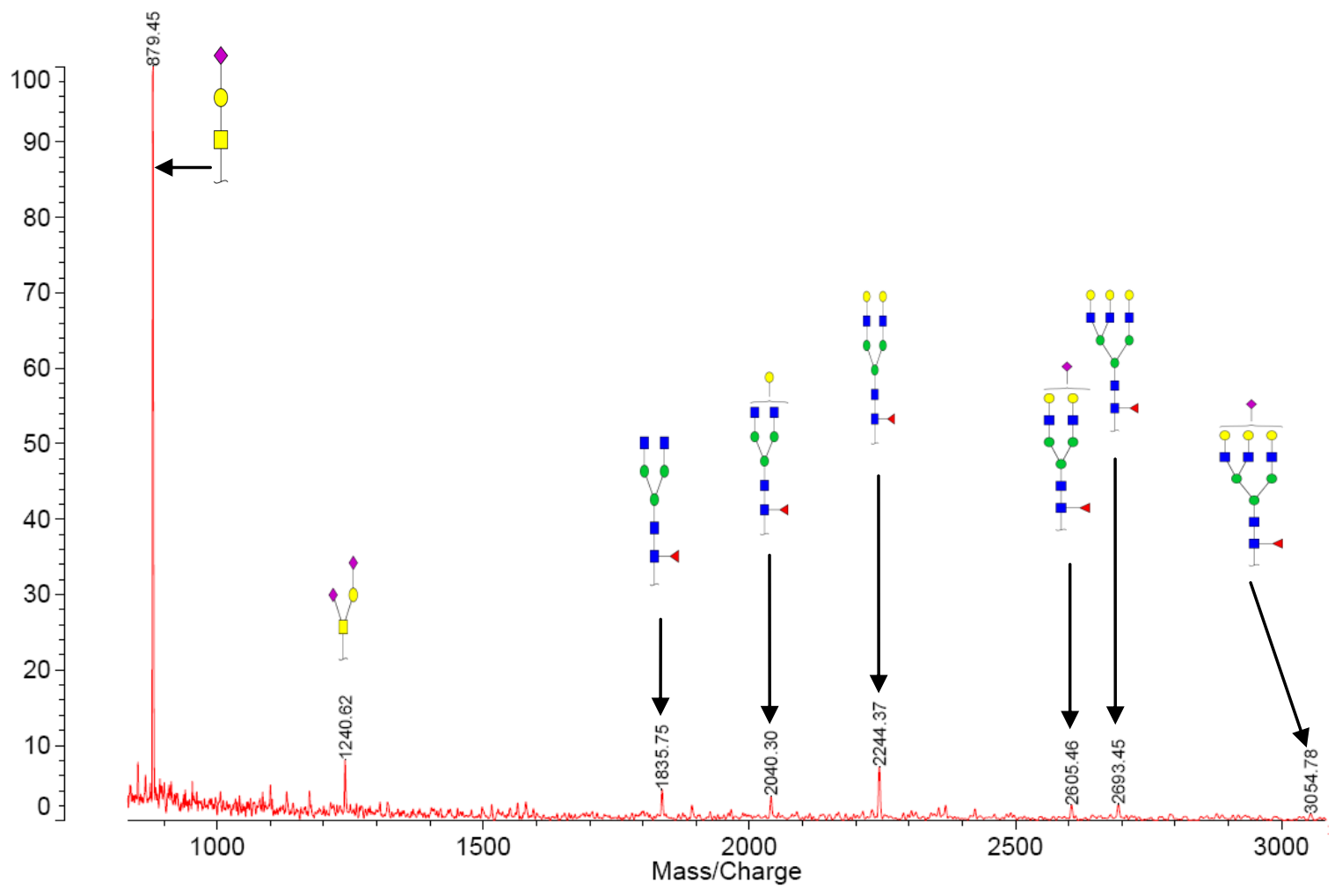

Fig. 2. MALDI-TOF mass spectrum for CD24 O-and N-glycans released by the ammonia based $\beta$ elimination method and permethylated. $\quad{ }^{\bullet}$-Fucose (Fuc), ${ }^{\circ}$ Galactose (Gal), $\quad{ }^{\bullet}$-Mannose (Man), $\quad$ N-AcetylGalactosamine (GalNAc), - -N-AcetylGlucosamine (GlcNAc), - $-\mathrm{N}-5$ Acetylneuraminic acid (NeuAc)

\subsection{Tandem mass spectrometry of the released $O$ - glycans}

The O-oligosaccharides released by the $\beta$ elimination chemical method were analyzed with ES-ion trap MS before permethylation. The nomenclature used for the fragmentation of the glycans was the one introduced by Domon and Costello [35]. In the nomenclature two types of fragmentation occur; glycosidic cleavage between the sugars ( $\mathrm{Y}$ and $\mathrm{Z}$ ) and cross ring cleavage $(\mathrm{X})$. The scheme of the fragmentation is shown in Figure 3.

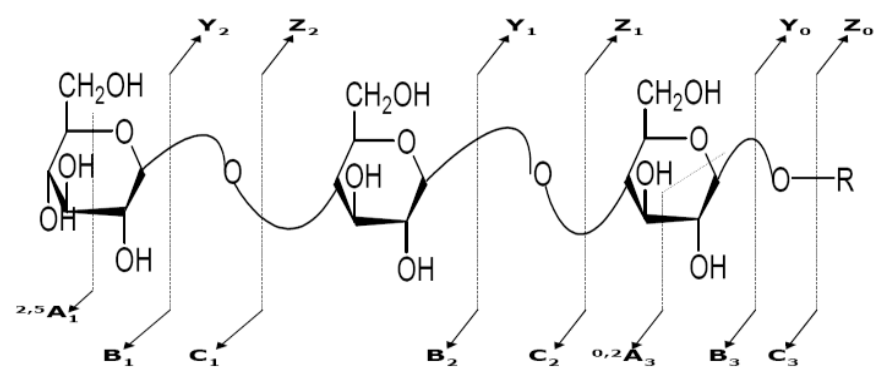

Fig. 3. Nomenclature for the fragmentation of carbohydrates.

The fragmentation provides information on the sugar sequence of the carbohydrate. In the 
results, the following peaks were positively identified. The peak at $m / z 675.4$ (Figure 4a) in the negative scan mode is a glycan whose structure has NeuAc $_{1} \mathrm{Hex}_{1} \mathrm{HexNAc}_{1}$. The CID fragmentation $\mathrm{MS}^{2}$ spectra (Figure $4 \mathrm{~b}$ ) revealed $\mathrm{m} / z$ ion $290\left(\mathrm{~B}_{1}\right)$ which was due to the loss of $\mathrm{N}$ - acetyl neuraminic acid and at $384\left(\mathrm{Y}_{2}\right)$, $\mathrm{Hex}_{1} \mathrm{HexNAc}_{1}$. This fragment represents the core 1 of the O-glycans, Gal $\beta-1,3$ GalNAc. Therefore, this peak's structure is proposed as Neu5Ac $\alpha$ 2,3/6Gal $\beta-1,3$ GalNAc.
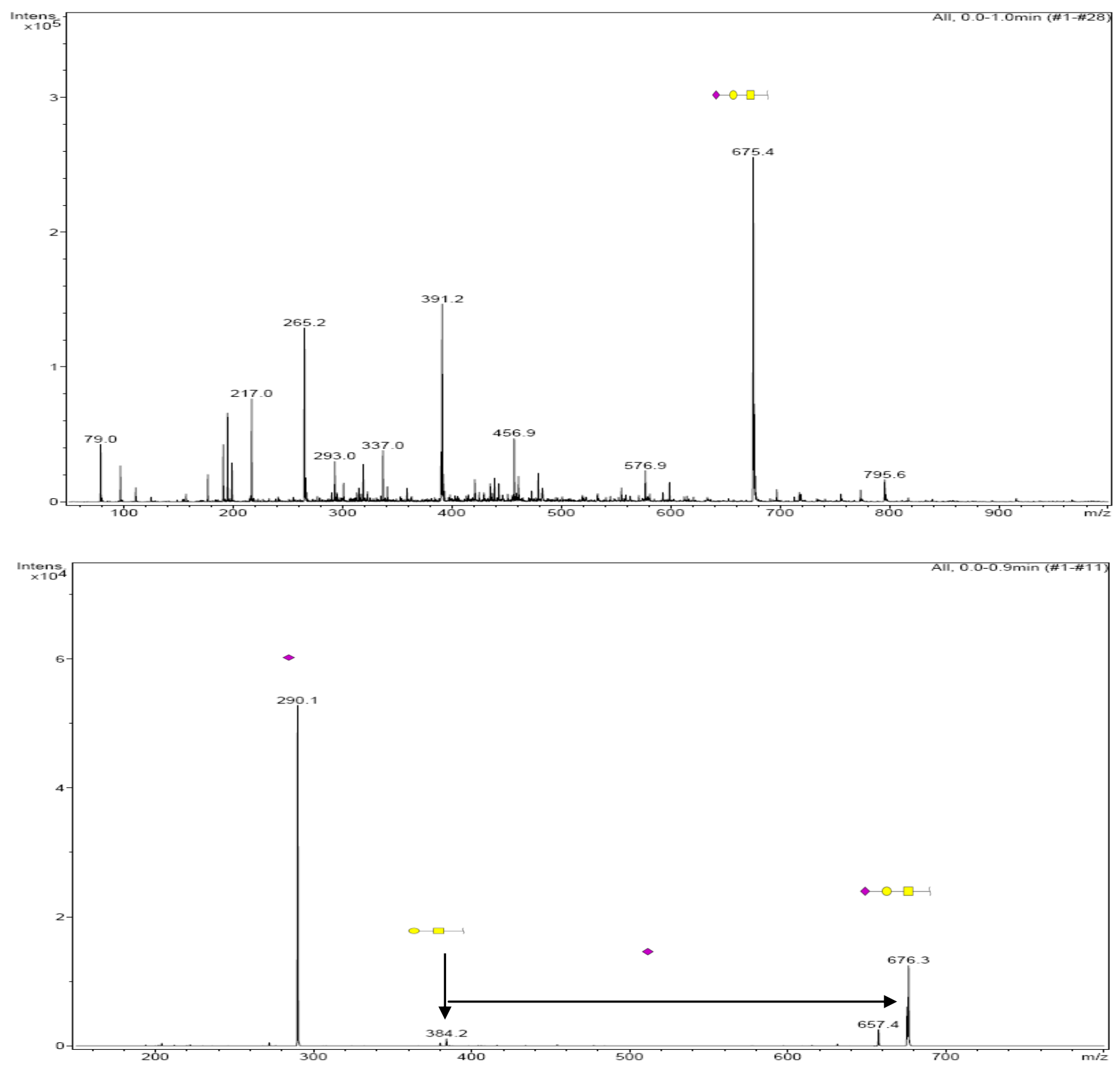

Fig. 4. a) Negative ion spectra of O-glycans released from CD24 by $\beta$-elimination and b) the negative scan mode fragmentation spectra of the $\mathrm{m} / \mathrm{z} 675.4$ ion. The sample was dissolved in $25 \%$ methanol in $1 \%$ acetic acid.

The structures of the released $\mathrm{O}-$ and $\mathrm{N}$ glycans from CD24 can be proposed because the glycosyltransferases and glycosidases in the ER and the Golgi apparatus have been identified. This limits the number of possible oligosaccharide structures to a small number. Table 1 summarizes the proposed structures of the O-glycans identified from the CD24 glycoprotein. 
Table I. O-glycans released from CD24 by a $\beta$-elimination with subsequent permethylation

\begin{tabular}{|c|c|c|c|c|}
\hline Sugars from CD24 & Observed Mol. Wt. & Expected ion molecular wt & Error, ppm & Proposed structure $^{\mathrm{a}}$ \\
\hline $\mathrm{NeuAc}_{1} \mathrm{Gal}_{1} \mathrm{GallNA}_{1}$ & 879.45 & 879.4316 & -20 & \\
\hline $\mathrm{NeuAc}_{2} \mathrm{Gal}_{1} \mathrm{GalNAc}_{1}$ & 1240.62 & 1240.6054 & -11 & \\
\hline
\end{tabular}

a ^-Fuc, ${ }^{\circ}$ Gal, $\bullet$-Man, $\square$-GalNAc, $\cdot-$ GlcNAc, •-NeuAc

The glycan Neu5Ac $\alpha-2,3 / 6 \mathrm{Gal} \beta-1,3 \mathrm{GalNAc}$ as seen in the mass spectra in Figure 2 was the most abundant oligosaccharide from CD24 with the other O-glycan from the glycoprotein being $\mathrm{NeuAc}_{2} \mathrm{Gal}_{1} \mathrm{GalNAc}_{1}$. The O-glycan identified as Neu5Ac $\alpha-2,3 / 6 \mathrm{Gal} \beta-1,3 \mathrm{GalNAc}$ is also called sialyl-T antigen. We report for the first time the presence of sialyl-T antigen in CD24. Mucin-like carbohydrates which include sialyl-T antigen, Tn, sialyl-Tn, and $\mathrm{T}$ antigen have been found to be expressed in some benign and malignant cancer cells. Moreover, sialyl-T and $\mathrm{T}$ antigen can be used as biomarkers in progression of several carcinomas [36-49]. The antigens have been found to be expressed in gastric carcinomas such as colon cancer $[37,39]$, breast carcinomas $[43,50]$, salivary gland carcinomas [38, 45-49], cancer of the human cervix [36], pancreatic tumors [42], ovarian tumors [44] and skin tumors [40, 41]. Since many of these cell types also over-express CD24 [20-22], it is intriguing that the CD24 overexpression may account for the increased sialyl-T in the cancer cells.

\subsection{N-glycans}

The CD24 N-glycans that were released with the use of PNGase $F$ were permethylated and analyzed with MALDI-TOF-MS. The mass spectrum of the oligosaccharides obtained is shown in Figure 5. The results showed three major peaks.

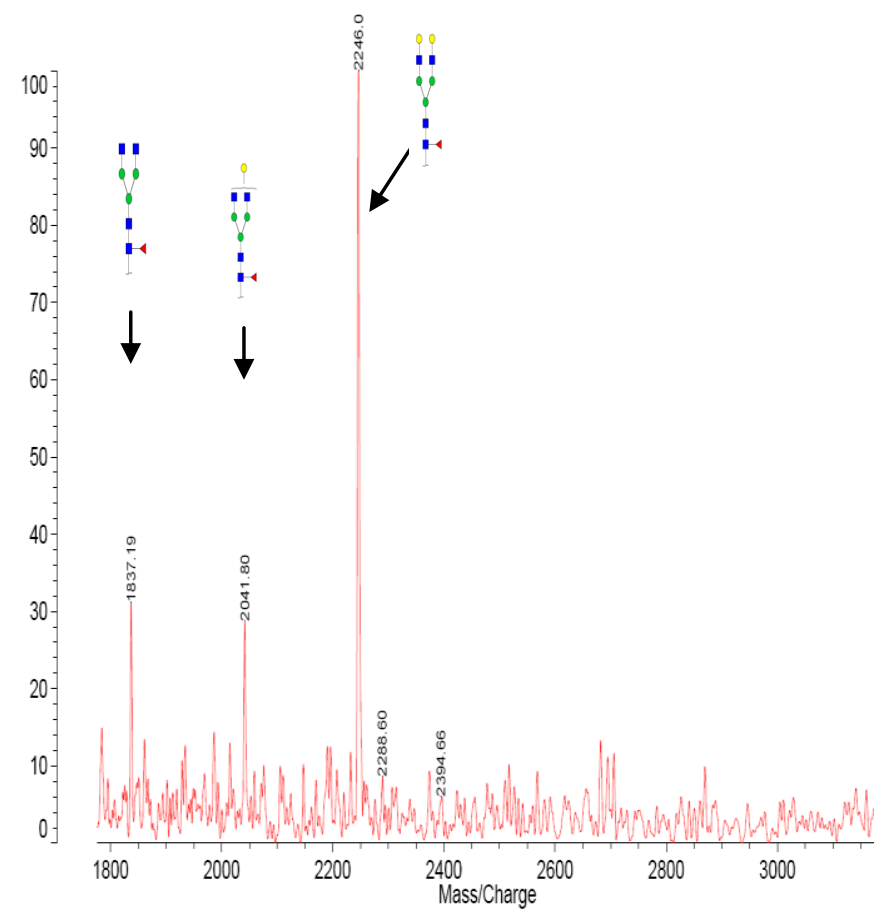

Fig. 5. MALDI-TOF mass spectrum for the permethylated $\mathrm{N}$-glycans released by PNGase $\mathrm{F}$ from CD24.

The peak at $\mathrm{m} / \mathrm{z}, 1836.88$ was identified as GalNAc $_{2}$ GlcNAc$_{2} \mathrm{Man}_{3} \mathrm{Fuc}_{1}$, at $\mathrm{m} / z 2041.88$ was $\mathrm{Gal}_{1} \mathrm{GalNAc}_{2} \mathrm{GlcNAc}_{2} \mathrm{Man}_{3} \mathrm{Fuc}_{1}$ and $\mathrm{m} / \mathrm{z} 2246.0$ was $\mathrm{Gal}_{2} \mathrm{GalNAc}_{2} \mathrm{GlcNAc}_{2} \mathrm{Man}_{3} \mathrm{Fuc}_{1}$. The Nglycans released here are similar to those released with the ammonia based $\beta$-elimination method (Figure 2). The $\mathrm{N}$ - glycans that were identified from Figures 2 and 5 are listed in Table 2 with their proposed structures. 
Table II. Permethylated N-glycans from CD24 released by PNGase F and ammonia based $\beta$-elimination method.

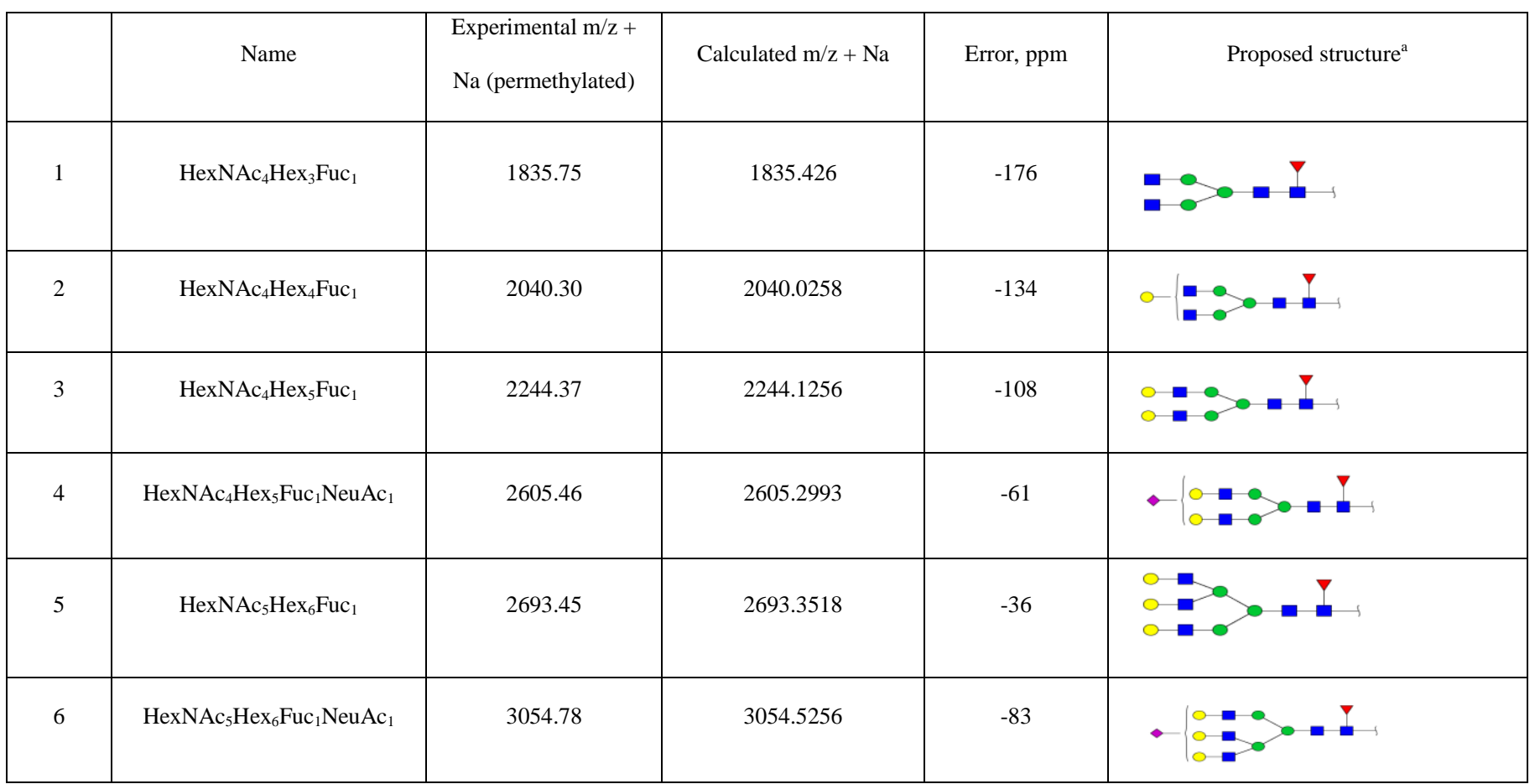

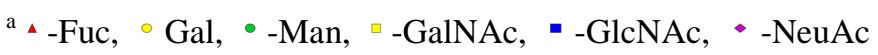

From these results, it can be observed that all the $\mathrm{N}$-glycans obtained are fucosylated. Studies on the binding of selectins to fucosylated carbohydrates have shown that glycoprotein with the Lewis ${ }^{\mathrm{x}}$ epitopes act as ligands for various selectins [51, 52]. These data suggest that oligosaccharides on the surface of CD24 can contribute towards the metastasis of tumors in cases where the protein is expressed.

The CD24 glycoprotein has 30 amino acids [2] with a predicted MW of $2929 \mathrm{Da}$. Since papain cut below the hinge region, another 10 amino acids are likely to be added in the CD24 glycoprotein used in this study. From the CD24 amino acid sequence, it has four potential $\mathrm{N}$ glycosylation sites and a total of sixteen serine and threonine amino acids which are potential Oglycosylation sites. As such, more than $80 \%$ of the mass in CD24 are oligosaccharides. Since the oligosaccharide Neu5Ac $\alpha-2,3 / 6 \mathrm{Gal} \beta-1,3 \mathrm{GalNAc}$, contributes more than half the total amount of the glycans in the CD24 glycoprotein, the glycans must be attached to the several serines and threonines of the glycoprotein.

\section{Acknowledgements}

The authors thank Richard Sessler of The Ohio State University Campus Chemical Instrumentation Center for the assistance in running the Bruker Esquire LC/MS instrument for $\mathrm{MS}^{\mathrm{n}}$ data. They would also like to thank HsiuFang Lee and Zhuojun Zhao of The Ohio State University College of Pharmacy for assistance in running the MALDI-TOF-MS. This work was supported by NIH CounterACT Program Center Grant U54NS058183 (to P. G. Wang), SBIR Phase II grant from National Institute of Health 5R44NS041692-03 (to OncoImmune), and by a Biomedical Research Technology Transfer Fund from the state of Ohio. 


\section{References:}

[1] M. Sammar, S. Aigner, and P. Altevogt, Heatstable antigen (mouse CD24) in the brain: dual but distinct interacton with P-selectin and L1, Biochimica et Biophysica Acta, 1997, 1337, 287294.

[2] R. Kay, F. Takei, and R. K. Humphries, Expression cloning of a cDNA encoding M1/69J11d heat-stable antigens, J. Immunol., 1990, 145, 1952-1959.

[3] C. Ohl, C. Albach, P. Altevogt, and B. Schmitz, N-glycosylation patterns of HSA/CD24 from different cell lines and brain homogenates: a comparison, Biochimie, 2003, 85, 565-573.

[4] G. Kristiansen, C. Denkert, K. Schluns, E. Dahl, C. Pilarsky, and S. Hauptmann, CD24 is expressed in ovarian cancer and is a new independent prognostic marker of patient survival, Am. J. Pathol., 2002, 161, 1215-1221.

[5] G. Kristiansen, K. J. Winzer, E. Mayordomo, J. Bellach, K. Schluns, C. Denkert, E. Dahl, C. Pilarsky, P. Altevogt, H. Guski, and M. Dietel, CD24 expression is a new prognostic marker in breast cancer, Clin. Cancer Res., 2003, 9, 49064913.

[6] S. C. Lim, and S. H. Oh, The role of CD24 in various human epithelial neoplasias, Pathol. Res. Pract., 2005, 201, 479-486.

[7] J. A. Zarn, S. M. Zimmermann, M. K. Pass, R. Waibel, and R. A. Stahel, Association of CD24 with the kinase c-fgr in a small cell lung cancer cell line and with the kinase lyn in an erythroleukemia cell line, Biochem. Biophys. Res. Commun., 1996, 225, 384-391.

[8] Y. Liu, B. Jones, A. Aruffo, K. M. Sullivan, P. S. Linsley, and C. A. Janeway, Jr., Heat-stable antigen is a costimulatory molecule for CD4 T cell growth, J. Exp. Med., 1992, 175, 437-445.

[9] Y. Liu, B. Jones, W. Brady, C. A. Janeway, Jr., P. S. Linsley, and P. S. Linley, Co-stimulation of murine CD4 $\mathrm{T}$ cell growth: cooperation between B7 and heat-stable antigen [published erratum appears in Eur J Immunol 1993 Mar;23(3):780], Eur. J. Immunol., 1992, 22, 2855-2859.

[10] X. F. Bai, O. Li, Q. Zhou, H. Zhang, P. S. Joshi, X. Zheng, Y. Liu, Y. Wang, and P. Zheng, CD24 Controls Expansion and Persistence of Autoreactive $\mathrm{T}$ Cells in the Central Nervous
System during Experimental Autoimmune Encephalomyelitis, J. Exp. Med., 2004, 200, 447458.

[11] Y. Lui, X.-F. Bai, Q. Zhou, O. Li, and P. Zheng, CD24 in experimental autoimmune encephalomyelitis and multiple sclerosis: Targeting redundancy for immunotherapy?, Current Immunology Reviews, 2005, 1, 173-176.

[12] O. Li, P. Zheng, and Y. Liu, CD24 expression on $\mathrm{T}$ cells is required for optimal $\mathrm{T}$ cell proliferation in lymphopenic host, J. Exp. Med., 2004, 200, 1083-1089.

[13] O. Li, X. Chang, H. Zhang, E. Kocak, C. Ding, P. Zheng, and Y. Liu, Massive and destructive $\mathrm{T}$ cell response to homeostatic cue in CD24-deficient lymphopenic hosts, J. Exp. Med., 2006, 203, 1713-1720.

[14] C. King, A. Ilic, K. Koelsch, and N. Sarvetnick, Homeostatic expansion of $\mathrm{T}$ cells during immune insufficiency generates autoimmunity, Cell, 2004, 117, 265-277.

[15] M. E. Dudley, J. R. Wunderlich, P. F. Robbins, J. C. Yang, P. Hwu, D. J. Schwartzentruber, S. L. Topalian, R. Sherry, N. P. Restifo, A. M. Hubicki, M. R. Robinson, M. Raffeld, P. Duray, C. A. Seipp, L. Rogers-Freezer, K. E. Morton, S. A. Mavroukakis, D. E. White, and S. A. Rosenberg, Cancer Regression and Autoimmunity in Patients After Clonal Repopulation with Antitumor Lymphocytes, Science, 2002, 298, 850-854.

[16] M. Hahne, R. H. Wenger, D. Vestweber, and P. J. Nielsen, The heat-stable antigen can alter very late antigen 4-mediated adhesion, J. Exp. Med., 1994, 179, 1391-395.

[17] G. Kilger, L. A. Needham, P. J. Nielsen, J. Clements, D. Vestweber, and B. Holzmann, Differential regulation of alpha 4 integrindependent binding to domains 1 and 4 of vascular cell adhesion molecule-1, J. Biol. Chem., 1995, 270, 5979-5984.

[18] D. Shewan, V. Calaora, P. Nielsen, J. Cohen, G. Rougon, and H. Moreau, mCD24, a glycoprotein transiently expressed by neurons, is an inhibitor of neurite outgrowth, J. Neurosci., 1996, 16, 2624-2634.

[19] Q. Zhou, K. Rammohan, S. Lin, N. Robinson, O. Li, X. Liu, X. F. Bai, L. Yin, B. Scarberry, P. Du, M. You, K. Guan, P. Zheng, and Y. Liu, $\mathrm{CD} 24$ is a genetic modifier for risk and 
progression of multiple sclerosis, Proc. Natl. Acad. Sci. U S A, 2003, 100, 15041-5046.

[20] T. Akashi, T. Shirasawa, and K. Hirokawa, Gene expression of CD24 core polypeptide molecule in normal rat tissues and human tumor cell lines, Virchows Arch, 1994, 425, 399-406.

[21] D. Jackson, R. Waibel, E. Weber, J. Bell, and R. A. Stahel, CD24, a signal-transducing molecule expressed on human B cells, is a major surface antigen on small cell lung carcinomas, Cancer Res., 1992, 52, 5264-5270.

[22] L. A. Williams, B. D. Hock, and D. N. Hart, Human $\mathrm{T}$ lymphocytes and hematopoietic cell lines express CD24-associated carbohydrate epitopes in the absence of CD24 mRNA or protein, Blood, 1996, 88, 3048-3055.

[23] S. Aigner, M. Ruppert, M. Hubbe, M. Sammar, Z. Sthoeger, E. C. Butcher, D. Vestweber, and P. Altevogt, Heat stable antigen (mouse CD24) supports myeloid cell binding to endothelial and platelet P-selectin, Int. Immunol., 1995, 7, 1557-1565.

[24] S. Aigner, Z. M. Sthoeger, M. Fogel, E. Weber, J. Zarn, M. Ruppert, Y. Zeller, D. Vestweber, R. Stahel, M. Sammar, and P. Altevogt, CD24, a mucin-type glycoprotein, is a ligand for P-selectin on human tumor cells, Blood, 1997, 89, 3385-3395.

[25] S. Aigner, C. L. Ramos, A. HafeziMoghadam, M. B. Lawrence, J. Friederichs, P. Altevogt, and K. Ley, CD24 mediates rolling of breast carcinoma cells on P-selectin, Faseb J., 1998, 12, 1241-1251.

[26] G. Kristiansen, C. Pilarsky, J. Pervan, B. Sturzebecher, C. Stephan, K. Jung, S. Loening, A. Rosenthal, and M. Dietel, CD24 expression is a significant predictor of PSA relapse and poor prognosis in low grade or organ confined prostate cancer, Prostate, 2004, 58, 183-192.

[27] R. Kay, P. M. Rosten, and R. K. Humphries, $\mathrm{CD} 24$, a signal transducer modulating $\mathrm{B}$ cell activation responses, is a very short peptide with a glycosyl phosphatidylinositol membrane anchor, J. Immunol., 1991, 147, 1412-1416.

[28] H. Leibiger, D. Wustner, R. D. Stigler, and U. Marx, Variable domain-linked oligosaccharides of a human monoclonal IgG: structure and influence on antigen binding, Biochem. J., 1999, 338 ( Pt 2), 529-538.
[29] Y. Huang, Y. Mechref, and M. V. Novotny, Microscale nonreductive release of O-linked glycans for subsequent analysis through MALDI mass spectrometry and capillary electrophoresis, Anal. Chem., 2001, 73, 6063-6069.

[30] N. Kotani, and S. Takasaki, Analysis of Olinked oligosaccharide alditols by high-pH anionexchange chromatography with pulsed amperometric detection, Anal. Biochem., 1997, 252, 40-47.

[31] S. M. Andrew, and J. A. Titus in Curent protocols in immunology (Coligan, J. E., Ed.), 1997, Vol. supplement 21, pp. 2.8.1, John wiley \& Sons, Inc.

[32] N. H. Packer, M. A. Lawson, D. R. Jardine, and J. W. Redmond, A general approach to desalting oligosaccharides released from glycoproteins, Glycoconj. J., 1998, 15, 737-747.

[33] P. Kang, Y. Mechref, I. Klouckova, and M. V. Novotny, Solid-phase permethylation of glycans for mass spectrometric analysis, Rapid Commun. Mass Spectrom., 2005, 19, 3421-3428.

[34] K. L. Bennett, S. V. Smith, R. J. Truscott, and M. M. Sheil, Monitoring papain digestion of a monoclonal antibody by electrospray ionization mass spectrometry, Anal. Biochem., 1997, 245, 17-27.

[35] B. Domon, and C. E. Costello, A systematic nomenclature for carbohydrate fragmentations in FAB-MS/MS spectra of glycoconjugates, Glycoconjugate Journal, 1988, 5, 397.

[36] C. Carrilho, M. Cantel, P. Gouveia, and L. David, Simple mucin-type carbohydrate antigens (Tn, sialosyl-Tn, T and sialosyl-T) and gp 230 mucin-like glycoprotein are candidate markers for neoplastic transformation of the human cervix, Virchows Arch, 2000, 437, 173-179.

[37] L. David, J. M. Nesland, H. Clausen, F. Carneiro, and M. Sobrinho-Simoes, Simple mucin-type carbohydrate antigens (Tn, sialosyl-Tn and $\mathrm{T}$ ) in gastric mucosa, carcinomas and metastases, APMIS Suppl, 1992, 27, 162-172.

[38] I. Fonseca, J. Costa Rosa, A. Felix, M. H. Therkildsen, U. Mandel, and J. Soares, Simple mucin-type carbohydrate antigens ( $T, T n$ and sialosyl-Tn) in mucoepidermoid carcinoma of the salivary glands, Histopathology, 1994, 25, 537543.

[39] S. H. Itzkowitz, M. Yuan, C. K. Montgomery, T. Kjeldsen, H. K. Takahashi, W. L. Bigbee, and 
Y. S. Kim, Expression of Tn, sialosyl-Tn, and T antigens in human colon cancer, Cancer Res., 1989, 49, 197-204.

[40] J. Kanitakis, I. al-Rifai, M. Faure, and A. Claudy, Thomsen-Friedenreich and its precursor (Tn) antigen expression in normal skin and in benign cutaneous tumours: a marker for sebaceous differentiation, Acta Derm. Venereol., 1998, 78, 173-76.

[41] J. Kanitakis, I. al-Rifai, M. Faure, and A. Claudy, Differential expression of the cancer associated antigens $\mathrm{T}$ (Thomsen-Friedenreich) and Tn to the skin in primary and metastatic carcinomas, J. Clin. Pathol., 1998, 51, 588-592.

[42] M. Osako, S. Yonezawa, B. Siddiki, J. Huang, J. J. Ho, Y. S. Kim, and E. Sato, Immunohistochemical study of mucin carbohydrates and core proteins in human pancreatic tumors, Cancer, 1993, 71, 2191-2199.

[43] W. Reed, M. Bryne, H. Clausen, E. Dabelsteen, and J. M. Nesland, Simple mucins (T, sialosyl-T, Tn and sialosyl-Tn) are not diagnostic for malignant breast lesions, Anticancer Res., 1994, 14, 609-615.

[44] Y. Tashiro, S. Yonezawa, Y. S. Kim, and E. Sato, Immunohistochemical study of mucin carbohydrates and core proteins in human ovarian tumors, Hum. Pathol., 1994, 25, 364-372.

[45] M. H. Therkildsen, Epithelial salivary gland tumours. An immunohistological and prognostic investigation, APMIS Suppl, 1999, 95, 1-39.

[46] M. H. Therkildsen, L. J. Andersen, M. Christensen, H. S. Hansen, T. Schiodt, and E. Dabelsteen, Salivary gland carcinomas: prognostic significance of simple mucin-type carbohydrate antigens, Oral Oncol., 1998, 34, 44-51.

[47] M. H. Therkildsen, U. Mandel, M. Christensen, H. Clausen, and E. Dabelsteen, Simple mucin-type carbohydrate antigens in pleomorphic adenomas, Apmis, 1993, 101, 242248.

[48] M. H. Therkildsen, U. Mandel, M. Christensen, and E. Dabelsteen, Simple mucintype Tn and sialosyl-Tn carbohydrate antigens in salivary gland carcinomas, Cancer, 1993, 72, 1147-1154.

[49] M. H. Therkildsen, U. Mandel, J. Thorn, M. Christensen, and E. Dabelsteen, Simple mucintype carbohydrate antigens in major salivary glands, J. Histochem. Cytochem., 1994, 42, 12511259.

[50] F. C. Schmitt, P. Figueiredo, and M. Lacerda, Simple mucin-type carbohydrate antigens (T, sialosyl-T, Tn and sialosyl-Tn) in breast carcinogenesis, Virchows Arch, 1995, 427, 251258.

[51] J. B. Lowe, Selectin ligands, leukocyte trafficking, and fucosyltransferase genes, Kidney Int FIELD Full Journal Title:Kidney international, 1997, 51, 1418-426.

[52] P. R. Crocker, and T. Feizi, Carbohydrate recognition systems: functional triads in cell-cell interactions, Curr. Opin. Struct. Biol., 1996, 6, 679-691. 